\title{
Global Research Trends, Top-100 Most Cited Studies, and Network Visualization of Eating and Feeding Disorders Research From 1900- 2020: A Historical Bibliometric Analysis
}

\author{
Muhammad Waseem Shah ${ }^{1}$ (D), Tauseef Ahmad ${ }^{2}$ (D), Muhammad Khan ${ }^{3}$ (D), Guiju Sun ${ }^{1 *}$ (D)
}

\author{
${ }^{1}$ Key Laboratory of Environmental Medicine and Engineering of Ministry of Education, and Department of Nutrition and Food Hygiene, School of Public Health, \\ Southeast University, Nanjing, CHINA \\ 'Department of Epidemiology and Health Statistics, School of Public Health, Southeast University, Nanjing, CHINA \\ ${ }^{3}$ Department of Biotechnology and Genetic Engineering, Centre for Human Genetics, Hazara University, Mansehra, PAKISTAN \\ *Corresponding Author: gjsun@seu.edu.cn
}

Citation: Shah MW, Ahmad T, Khan M, Sun G. Global Research Trends, Top-100 Most Cited Studies, and Network Visualization of Eating and Feeding Disorders Research From 1900-2020: A Historical Bibliometric Analysis. Electron J Gen Med. 2022;19(3):em368. https://doi.org/10.29333/ejgm/11839

ARTICLE INFO

Received: 5 Jan. 2022

Accepted: 25 Feb. 2022

\begin{abstract}
Background: Eating disorders (EDs) are psychiatric disorders that leads to affect the health. In last few decades, EDs have been rising rapidly due to disturbed attitudes towards eating that play a critical role in the maintenance of EDs. This study was performed to assess key bibliometric indicators, visualize the research outcomes in the field, and find the current trends in EDs.
\end{abstract}

Methods: A comprehensive search was conducted utilizing the Web of Science Core Collection (WoSCC) database. The obtained data was imported into Microsoft Excel 2019 and VOSviewer software for windows. The database search was performed for the period from the inception of WoSCC until 2020. The downloaded data was exported into VOSviewer software version 1.6.16 for Windows to construct co-authorship countries, keywords cooccurrence, and journal and organization sources network visualization.

Results: The initial search yielded 16,693 publications, of which 11,322 articles were included in the overall analysis. Furthermore, the top-100 most cited papers were included based on number of citations in descending order. The average citation per year for overall publications $(n=11,322)$ was 830.92 and that of top- 100 most cited papers was 490.24. The study authored by Fairburn and Beglin in year 1994 received the highest citations $(2,999)$. Among the top-100 highly cited articles, Fairburn CG was the most prolific author with 10 publications $(6,254$ citations). The frequently studied research area was psychiatry, and the leading source of publication was Archives of General Psychiatry with 20 published articles and 7,872 citations. The analysis of the overall articles indicted that International Journal of Eating Disorders got 2,500 publications and 88,921 citation score. The University of Minnesota was first in top-100 most cited articles for maximum number of publications $(n=12)$ but from the overall analysis of all the articles, Harvard University was first with a total of 405 publications. The United States of America was the most prominent country with 58 number of documents.

Conclusion: Majority of articles were produced by developed countries. Hence, there is a dire need for interdisciplinary research approaches to evaluate and intervene Eds. We believe that the highly cited articles in feed and EDs may help to some future novel ideas and regulate effective preventive strategies.

Keywords: eating disorders, bibliometric analysis, VoSviewer

\section{INTRODUCTION}

Eating disorders (EDs) are serious psychiatric illnesses characterized by abnormal eating habits with severe concerns about food, body weight, and shape that affect psycho-social functions or physical health. Disturbed attitudes toward weight, body shape, and eating play a key role in origin of EDs $[1,2]$. EDs are prevalent and significantly associated with psychiatric and medical comorbidities [3,4]. The Handbook of Diagnostic and Statistical Manual of Mental Disorders fifth edition (DSM-5) is usually utilized by psychiatrists and clinicians in the United States for diagnosing psychiatric disorders and it has changed the terminology of EDs into "eating and feeding disorders" [1,5].

EDs as a well-defined field of research has relatively a long history, and the first online publication regarding eating disorder has been made in 19th century (year 1900) and published in German language [6]. EDs come with both emotional and physical symptoms including anorexia nervosa (AN-voluntary starvation), bulimia nervosa (BN-binge eating followed by purging) and binge eating disorder (BED-binge eating without purging) and hence represent a class of common and fatal psychiatric illnesses [7]. Preliminary evidence indicated a growth in the rates of anorexia nervosa, bulimia nervosa and binge eating disorder [8]. The different 
forms of eating disorders can intermingle pass over; bulimia can develop from anorexia nervosa and eventually develop an eating addiction (an unspecified eating disorder) and vice versa [9]. Approximately $17 \%$ of the US college women meet the criteria for high-ED-risk and those living in Muslim countries are at risk of developing a clinical ED. While several studies have reported differences in ED risk across racial and ethnic identities, and no consistent forms have emerged [10-12]

The term statistical bibliography was first used in 1922 by Hulme EW while delivering two lectures at the University of Cambridge, England. These lectures were published as a book $[13,14]$. This term then seemed to be ignored for twenty-two years until Gosnell FC used obsolescence of literature in his paper and did not acknowledge any previous usages $[15,16]$. The next use of the term was in 1962 by Raisig in a critical essay on citation studies [17]. Later Kendall MG suggested to change the name of the subject after receiving a copy of paper written by Pritchard A. In 1969, Pritchard A introduced and explained the term bibliometrics as 'the application of mathematical and statistical methods to books and other media of communication [18]. He believed that the nature of the term statistical bibliography was unclear and could be confused with statistics itself or bibliographies on statistics and thus suggested using the term bibliometrics rather than statistical bibliography [19]. Bibliometric analysis has emerged as a widely used statistical tool for evaluation of the quality, credibility, and the impact of scholarly work. It is also used to evaluate the scientific output for predicting and studying scientific progresses as well as the citation counts and collaboration in institutions, countries, authors, and journals [20-23]. Researchers can perform a quantitative evaluation of the distribution structure and growth of studies in papers by using methodological techniques of bibliometrics and hence reduce the impact of biasness on the quality of review $[24,25]$.

Several studies have evaluated the research output on eating disorders (EDs) by using sciento-metric methods [26.] Bibliometric techniques and graph-theory was used in one of the studies for identifying co-authorship and social network patterns; this study assessed the progression of multi-authors collaborations during 1980-2014 and evaluated their relationship with publication trends on eating disorders [27]. Published articles on EDs from year 1970 to 2011 were also identified by using PsycINFO and Medline databases and the profile of cross-cultural studies were analyzed [28]. In another 20-year bibliometric study on eating disorders, the authors evaluated the gender of the first and last author of all articles published in high impact psychiatry and clinical psychology journals including the eating disorder specialty journals from 1997 to 2016 [29]. In one other bibliometric review published in year 2014, the authors sought to identify top-100 cited papers in Anorexia Nervosa as well as the citation classics which have made a significant impact on the field and focused on papers dealing predominantly with AN only [30].

In recent years, the bibliometric types of studies have gained much attention to explore and analyze large scientific data, identify hot spot research areas, key bibliometric indicators, and network visualization [31-34]. Thus, the current study was conducted to get a clearer view of the research trends in eating and feeding disorders. We sought to identify and evaluate the overall articles and to compare it with the top100 most cited articles from year 1900 to 2020 in eating and feeding disorders along with the inclusion of anorexia nervosa, bulimia nervosa and binge eating disorder.

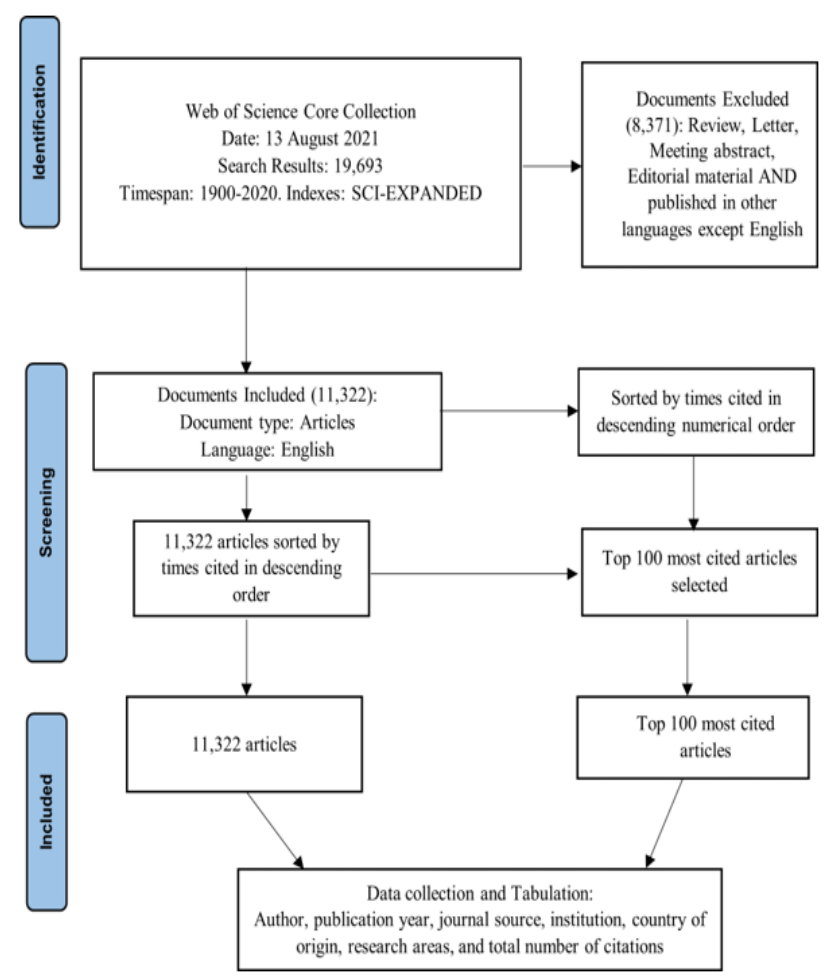

Figure 1. Flowchart of the search strategy

\section{METHODOLOGY}

\section{Data Source and Search Strategy}

Data related to the current study were retrieved from the Science Citation Index-Expanded (SCI-E) Edition of the Web of Science Core Collection (WoSCC) database by two independent investigators on 13 August 2021, yielding initial results $(\mathrm{N}=19,693)$. Only journal articles published in English language from year 1900 to 2020 were included.

\section{Search Keywords}

Medical subject heading (MeSH) terms from PubMed was referred for establishing search key words as follows: TITLE: (Eating and Feeding Disorders) OR TITLE: (Feeding Disorders) OR TITLE: (Disorders, Eating) OR TITLE: (Feeding Disorder) OR TITLE: (Eating Disorders) OR TITLE: (Eating Disorder) OR TITLE: (Anorexia Nervosa) OR TITLE: (Bulimia Nervosa) OR TITLE: (Binge eating disorder). The initial search results were continually filtered till stabilization of number of articles ( $n=11,322$ articles).

\section{Exclusion Criteria}

The document types such as reviews, letters, meeting abstracts and editorial materials were excluded as this current study just focused on original articles. The articles published in other languages except English were also excluded (Figure 1).

\section{Data Extraction}

After confirming search strategy, all the articles were arranged by time's cited in descending numerical order to identify top-100 most cited papers. Two autonomous researchers read the abstract or full text of each search result to screen all the relevant articles by inclusion and exclusion criteria. Data concerning authors, publication years, journal 


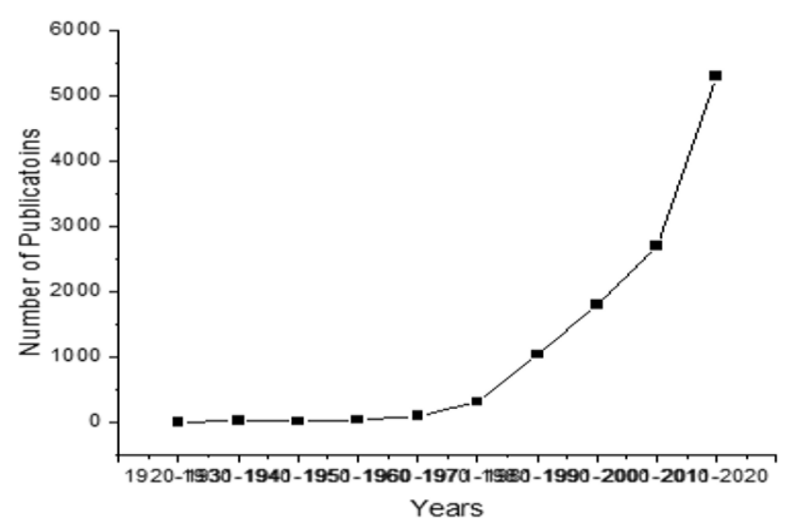

Figure 2. Publication trends by year in feeding-eating disorders

source, institution, country of origin, research areas, and total number of citations was extracted manually for overall analysis as well as for the analysis of top-100 most cited articles.

\section{Data Analysis and Visualization Mapping}

The data were downloaded in the form of plaintext and comma-separated value. The values of descriptive statistics are presented in the form of frequencies and percentages. The required graphs and figure were generated using OriginPro 2018. The obtained data were exported in to VOSviewer software version 1.16.1 for windows to plot the data for coauthorship countries, co-occurrence keywords, and journal and organization sources network visualization mapping.

\section{RESULTS}

The trends of publication in feeding and eating disorder is categorized in Figure 2. The global annual research productivity displayed a noteworthy increment during 19711980 and the research output reached up to maximum 5,302 publications in 2011-2020.

The characteristics of top-5 most cited papers (see Supplementary File for top-100) are presented in Table 1. The most cited paper was "Assessment of eating disordersinterview or self-report questionnaire" authored by Fairburn and Beglin and published in "International Journal of Eating Disorders" in 1994 and received total 2,999 citations. In this study a comparison between investigator-based interview and self-report questionnaire was done and both the methods performed the same in explicit behavioral features such as dieting and self-induced vomiting. However, self-report questionnaire received high scores in assessing complex features of eating disorders like binge eating and body shape concerns [35]. The second most cited paper was authored by Garner, Olmstead, and Polivy, entitled "Development and validation of a multidimensional eating disorder inventory for anorexia-nervosa and bulimia" and published in International Journal of Eating Disorders in year 1983 [36]. Total number of citations received for this paper are 2,946 and it focused on development and validation of EDI. In this study cross validation procedure was followed for differentiating patients with anorexia nervosa $(n=113)$ and $(n=577)$ female comparison

Table 1. Characteristics of top-5 most cited papers

\begin{tabular}{|c|c|c|c|c|}
\hline Authors & Year & Title & $\begin{array}{c}\text { Total } \\
\text { Citations }\end{array}$ & Bottom line \\
\hline $\begin{array}{l}\text { Fairburn \& } \\
\text { Beglin }\end{array}$ & 1994 & $\begin{array}{l}\text { Assessment of eating } \\
\text { disorders-interview or } \\
\text { self-report } \\
\text { questionnaire }\end{array}$ & 2,999 & $\begin{array}{l}\text { In this study, a detailed comparison between investigator-based interview and self- } \\
\text { report questionnaire was carried out to assess eating disorders features. Both the } \\
\text { methods performed similar when assessing the explicit behavioral features (dieting } \\
\text { and self-induced vomiting) while self-report questionnaire made high scores for } \\
\text { complex features (binge eating and body shape concerns). Moreover, bodyweight } \\
\text { was underestimated in both methods. }\end{array}$ \\
\hline Garner et al. & 1983 & $\begin{array}{l}\text { Development and } \\
\text { validation of a } \\
\text { multidimensional eating } \\
\text { disorder inventory for } \\
\text { anorexia-nervosa and } \\
\text { bulimia }\end{array}$ & 2,946 & $\begin{array}{l}\text { This study described the development and validation of eating disorder inventory } \\
\text { (EDI) which is a } 64 \text { item self-report multi-scale measure for assessing psychological } \\
\text { and behavioral characters in anorexia nervosa (AN) and bulimia. The results } \\
\text { indicated that the EDI is consistent and a valid assessment tool within the } \\
\text { parameters imposed by the selected samples. Eight sub-scales were deductively } \\
\text { derived and then analytically confirmed with the aim that they distinguish, with a } \\
\text { very slight overlap between patients with AN and females from a college } \\
\text { comparison group. }\end{array}$ \\
\hline Hudson et al. & 2007 & $\begin{array}{l}\text { The prevalence and } \\
\text { correlates of eating } \\
\text { disorders in the national } \\
\text { comorbidity survey } \\
\text { replication }\end{array}$ & 2,640 & $\begin{array}{l}\text { In this study WHO composite international diagnostic interview was used to assess } \\
\text { the prevalence and correlates of ED from the national comorbidity replication by } \\
\text { face-to-face household survey of 9,282 subjects, conducted in year } 2001 \text { to } 2003 \text {. } \\
\text { The estimates of lifetime prevalence for ED were found. However, in this study most } \\
\text { of the men were suffering with AN and bulimia nervosa. Lifetime AN was related } \\
\text { with a low current BMI. The lifetime prevalence of the individual eating disorders } \\
\text { was found to be } 0.6-4.5 \% \text {. }\end{array}$ \\
\hline $\begin{array}{l}\text { Garner \& } \\
\text { Garfinkel }\end{array}$ & 1979 & $\begin{array}{l}\text { Eating attitudes test- } \\
\text { index of the symptoms } \\
\text { of anorexia-nervosa }\end{array}$ & 2,175 & $\begin{array}{l}\text { This study reported data on the development of a } 40 \text {-item measure of the symptoms } \\
\text { in AN. The eating attitude test (EAT) was validated by two groups of female patients } \\
\text { with AN ( } n=32 \text { and } 33 \text { ) and female control subjects ( } n=34 \text { and } 59 \text { ). significant } \\
\text { correlation was found between Total EAT score and criterion group membership } \\
\text { ( } r=0.87, p<0.001 \text { ), signifying a high level of concurrent authenticity. Moreover, obese } \\
\text { female and male subjects also scored significantly lower on the EAT than anorexics. } \\
\text { Recovered anorexic patients got in the normal range on the test, suggesting EAT } \\
\text { sensitive to clinical remission. }\end{array}$ \\
\hline Russell & 1979 & $\begin{array}{l}\text { Bulimia nervosa - } \\
\text { ominous variant of } \\
\text { anorexia-nervosa }\end{array}$ & 1,255 & $\begin{array}{l}30 \text { patients were selected in this study under criteria (i) a desire to over-eat (bulimia } \\
\text { nervosa) followed by self-induced vomiting (or purging) and (ii) morbid fear of } \\
\text { getting fat. A theoretical model was described to highlight the interrelationship of } \\
\text { the various symptoms and the role of self-perpetuating mechanisms in the } \\
\text { maintenance of the disorder. The main aims of treatment were to intrude the } \\
\text { vicious group of over-eating and self-induced vomiting and to encourage the } \\
\text { patients to accept a higher weight. }\end{array}$ \\
\hline
\end{tabular}


Table 2. Publication record count and citation details of most productive authors

\begin{tabular}{lll}
\hline Author & Affiliation & Publications (Total citations) \\
\hline Fairburn, CG & Department of Psychiatry, Oxford University, UK & 10 (6,254) \\
\hline Doll, HA & Department of Public Health, Oxford University, UK & 5 (1,764) \\
\hline Herzog, DB & Harvard Medical School, Department of Psychiatry, USA & 5 (1,554) \\
\hline Bulik, CM & Department of Psychiatry, Virginia Institute for Psychiatric and Behavioral Genetics, USA & $4(1,627)$ \\
\hline Garfinkel, PE & Center for Addiction and Mental Health, Toronto, Canada & $4(3,499)$ \\
\hline Garner, DM & Department of Psychiatry, Michigan State University, Michigan & 4 (6,122) \\
\hline Halmi, KA & Department of Psychiatry, Cornell University Medical College, NY, USA & $4(1,396)$ \\
\hline Russell, GFM & Department of Psychiatry, The University of London, UK & $4(1,703)$ \\
\hline Welch, SL & Department of Psychiatry, Oxford University, UK & $4(1,411)$ \\
\hline
\end{tabular}

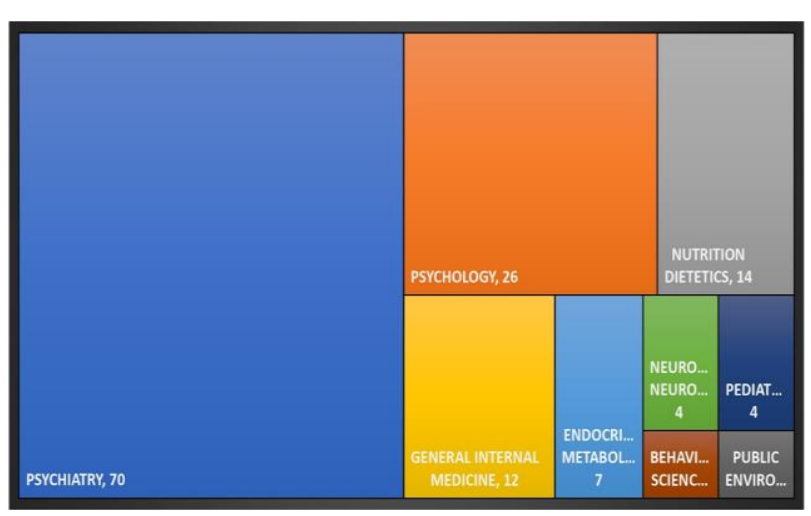

Figure 3. Research areas of top-100 most cited papers in eating disorders

group. Self-report subscale scores were agreed with subscale traits of clinician ratings, and clinically recovered patients of anorexia nervosa scored the same as female comparison subjects. Conclusively, convergent and discriminant validity were developed for sub-scales. The results indicated that the EDI is reliable and a valid assessment tool within the parameters imposed by the selected samples.

The third most cited paper was "The prevalence and correlates of eating disorders in the national comorbidity survey replication" which was published in a peer reviewed journal "Biological Psychiatry" in year 2007. Total 2,640 citations were received for this study and this study was based on WHO composite international diagnostic interview, which was used for the assessment of the prevalence and associates of eating disorders from the national comorbidity replication. The life-time prevalence of the individual ED was found to be 0.6-4.5 percent.

\section{Most Productive Authors (Minimum Four Publications)}

Table 2 shows the most productive authors who have contributed to the field of eating disorders. Among 408 authors of top-100 most cited papers, only nine met our inclusion criteria (minimum four publications each). Christopher $G$ Fairburn authored total 10 publications and received total of 6,254 citations; Helen A Doll and DB Herzog authored five publications each and received 1,764 and 1,554 citations, respectively. All the remaining from top-9 most productive authors, Bulik CM, Garfinkel PE, Garner DM, Halmi KA, Russell
GFM, and Welch SL published four documents each. The first two authors Christopher G Fairburn, Helen A Doll, and the one with least publications Welch SL (four publications, 1,411 citations) are affiliated with Oxford University, United Kingdom (UK) while in rest, three authors are from USA, one each from Canada and Michigan, and one from the University of London, UK.

\section{Contributions in Research Areas}

Figure 3 shows the contributions with respect to the research areas of top-100 most cited papers. The minimum records count was kept at two and most of the published documents among top-100 most cited papers regarding our area of interest (search strategy) were in the research area of psychiatry ( $n=70$ records). The second ranked area of research which got 26 number of records was psychology, while nutrition dietetics ( $n=14$ records) was ranked third. Total published documents in research area of general internal medicine were 12 while for the rest of five areas of research, were less than $10 \%$.

\section{Active Journals of Top-100 Most Cited and the Overall Papers}

For literature related to eating disorders, the highest cited journals (at-least five documents) along with the number of documents and impact factor (IF) were determined (Table 3). Only four journals met our selection criteria in which Archives of General Psychiatry was the leading journal with 20 documents and 7,872 citations. The impact factor of this journal is 21.596 by year 2020 .

The second most active journal in our field of interest was American Journal of Psychiatry (IF=18.112), which published 16 documents and received 5147 citations. International Journal of Eating Disorders with IF 4.861 by 2020 was ranked third with 10 number of documents but received the highest citation score of 9,524; Psychological Medicine from UK was ranked fourth with nine number of documents (5,932 citations) and IF 5.813 .

The visual network analysis of the overall articles in Figure 4 showed that International Journal of Eating Disorders was ranked first with 2,500 documents and 88,921 citation score and was followed by 'Eating and Weight Disorders-Studies on Anorexia Bulimia and Obesity' (474 documents, 3,544 citations) and 'Psychiatry Research' (307 documents, 8,200 citations).

Table 3. Top active journals among top-100 most cited papers

\begin{tabular}{|c|c|c|c|c|c|}
\hline Source & Documents & Citations & Total link strength & Impact factor (2020) & Country \\
\hline Archives of General Psychiatry & 20 & 7,872 & 65 & 21.596 & USA \\
\hline American Journal of Psychiatry & 16 & 5,147 & 44 & 18.112 & USA \\
\hline International Journal of Eating Disorders & 10 & 9,524 & 22 & 4.861 & USA \\
\hline Psychological Medicine & 9 & 5,932 & 33 & 5.813 & UK \\
\hline
\end{tabular}




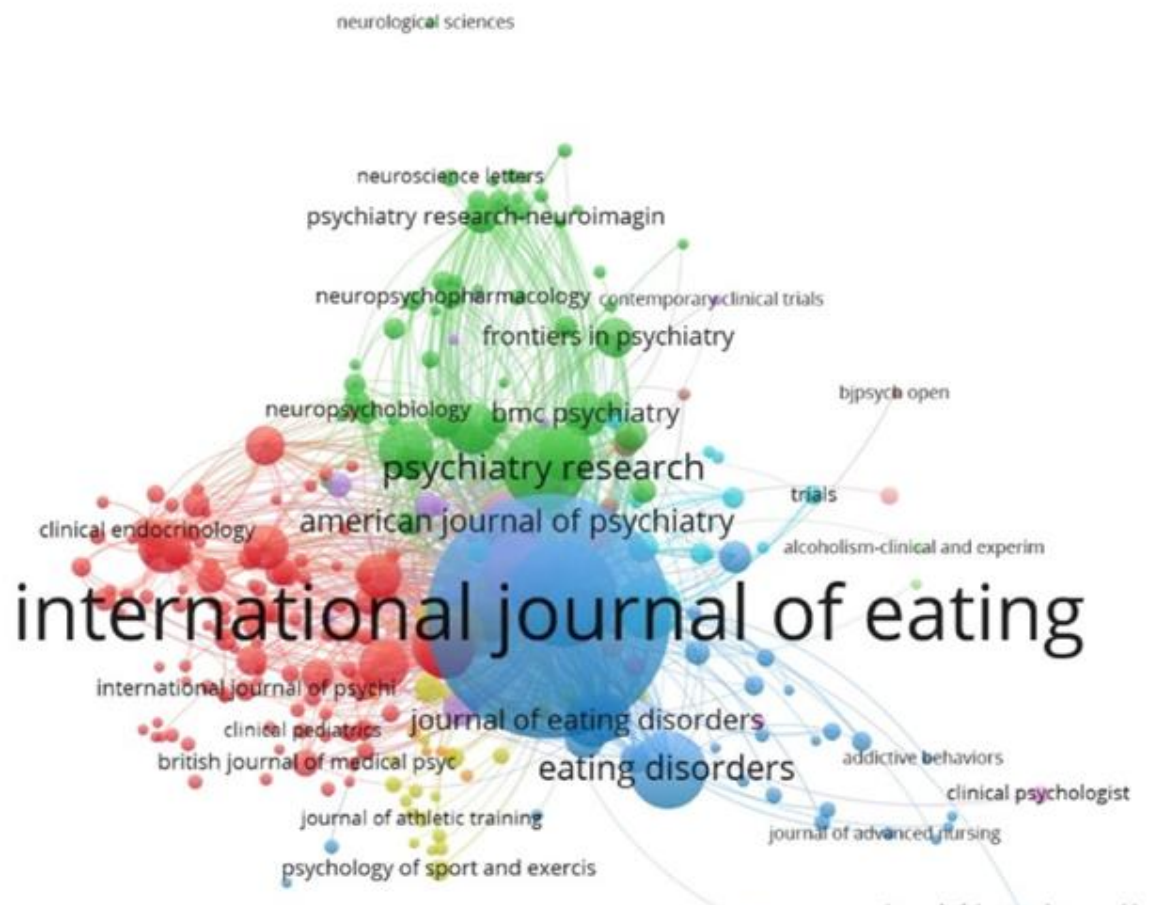

vosviewer

psychiatrie services

journal of the arberican psychia

Figure 4. Visualization network analysis of journal source of overall articles

Table 4. Institution/Organizations contributed to top-100 most cited articles in ED

\begin{tabular}{lccc}
\hline Organization & Documents & Citations & Total link strength \\
\hline The University of Minnesota & 12 & 5,321 & 29 \\
\hline Columbia University & 9 & 3,984 & 24 \\
\hline Harvard University & 8 & 5,041 & 31 \\
\hline Stanford University & 8 & 2,818 & 26 \\
\hline Oxford University & 7 & 5,274 & 25 \\
\hline Massachusetts General Hospital & 7 & 2,163 & \\
\hline University of Pittsburgh & 5 & 2,495 & \\
\hline National Institute of Mental Health & 5 & 2,677 & 16 \\
\hline
\end{tabular}

\section{Most Productive Institution/Organizations Among Top-100 Most Cited Papers}

By limiting number of documents published by an organization to five, total of eight organizations were found to be more productive (Table 4). The University of Minnesota located in USA ranked first for highest number of publications $(n=12)$ regarding eating disorders and received total of 5,321 citations.

Columbia University of New York, USA ranked second with nine publications (3,984 citations) and Harvard University and Standford University of USA were ranked third with eight number of documents each with citations of 5,041 and 2,818, respectively. Oxford University and Massachusetts General Hospital published seven documents each while the number of documents published by University of Pittsburgh and National Institute of Mental Health were five each and were ranked the last in top-8 contributing organizations.

\section{Most Productive Countries}

Total 22 countries contributed to top-100 most cited papers out of which only four met our selection criteria
Table 5. Country of origin of top-100 most cited articles

\begin{tabular}{lccc}
\hline Country & Documents & Citations & Total link strength \\
\hline USA & 58 & 24,992 & 90 \\
\hline England & 19 & 9,779 & 65 \\
\hline Canada & 5 & 4,358 & 15 \\
\hline The Netherlands & 5 & 2,333 & 32 \\
\hline
\end{tabular}

(published minimum four documents). USA was the top leading country with 58 number of documents and total citations 24,992. England published 19 documents with total 9,779 citations while Canada and Netherlands published five documents each and received citations of 4,358 and 2,333, respectively (Table 5).

\section{Network Mapping and Visualization}

VOS-viewer version 1.6.16 was used to generate network mapping and visualization of countries, all keywords' occurrences, and institutions of top-100 most cited and the overall articles. A total of 22 different countries contributed to co-authorship analysis among top-100 most cited articles; out of which only four countries met our selection criteria of minimum five publications (Figure 5). 


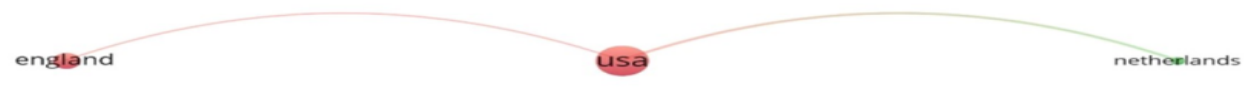

\section{fo vosviewer}

Figure 5. Co-authorship network analysis of countries (top-100 most cited articles)

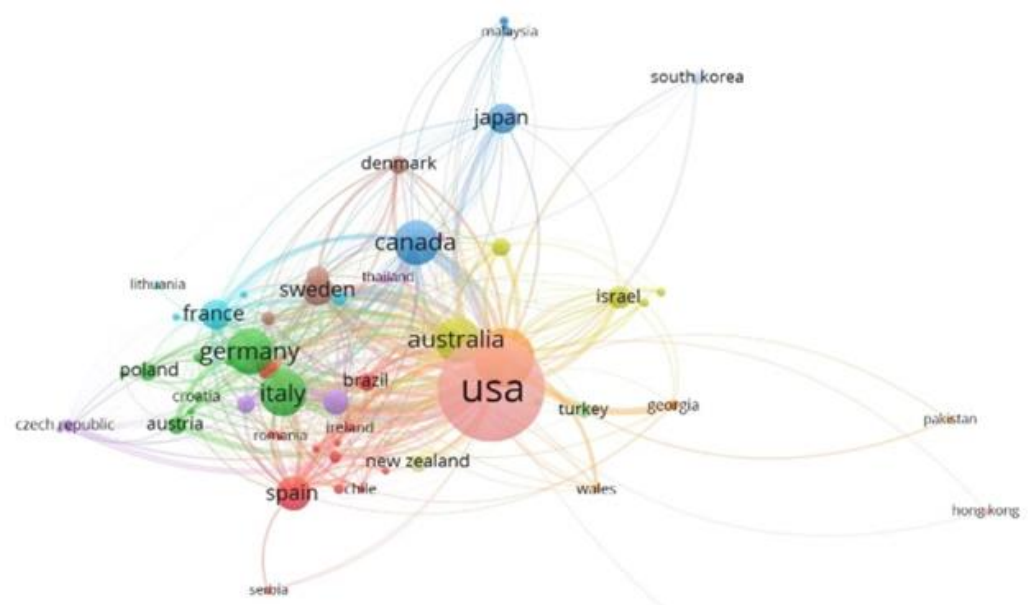

\section{\& vosviewer}

Figure 6. Co-authorship network analysis of countries (overall articles)

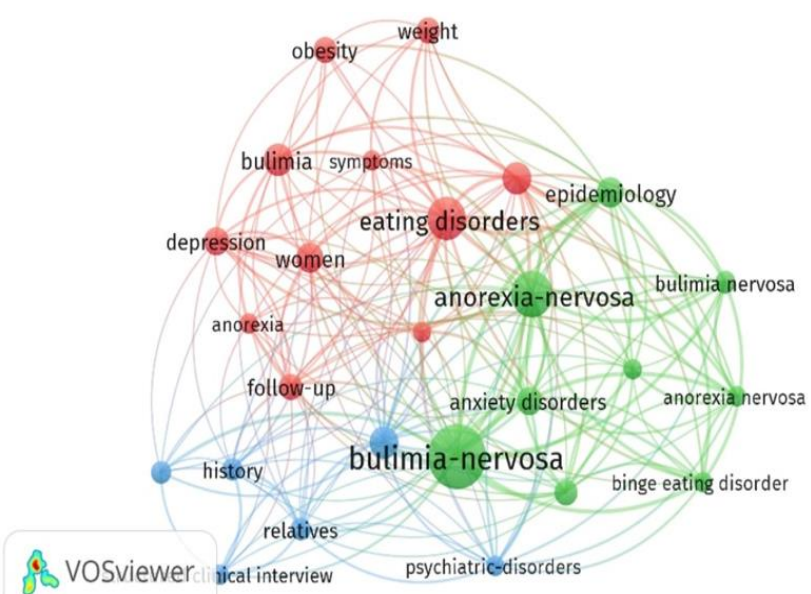

Figure 7. All keywords co-occurrence network (top-100 most cited articles)

USA was the most prolific country with ( $n=58$ articles) more than a half number of total articles followed by England $(n=19)$ and Canada and the Netherlands ( $\mathrm{n}=5$ each). The citation results of these countries are given in Table 5 which showed that USA received maximum citations $(n=24,992)$. When applying the same analysis (Figure 6) including the overall articles ( $n=11,322)$, USA was the top leading country with total of 4,225 documents and total link strength (TLS) of 1,063, followed by England ( $n=1,364$ documents, TLS 579) and Italy ( $n=826$ documents, TLS 202).

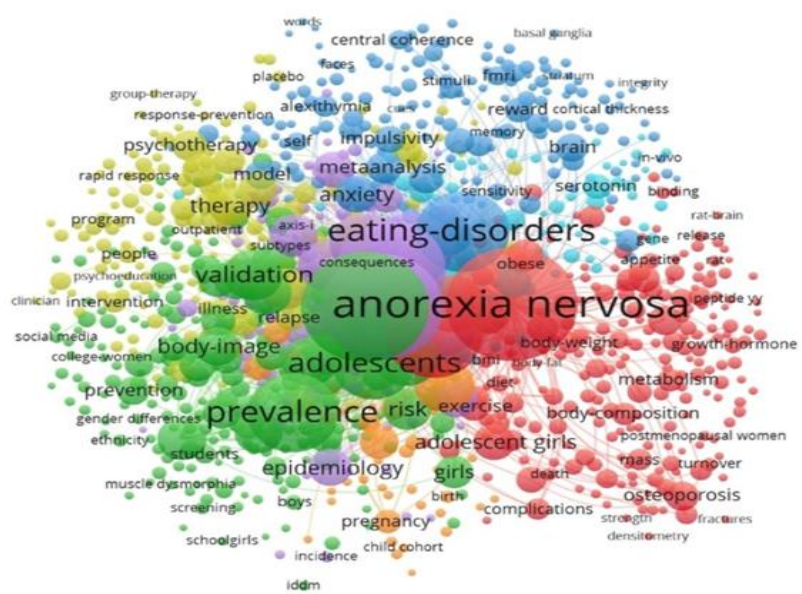

Figure 8. All keywords co-occurrence network (overall articles)

All keywords co-occurrence network of top-100 most cited articles is represented in a visual diagram (Figure 7). The number of occurrences of a keyword was limited to five and out of 365 keywords, 26 met the threshold. Bulimia-nervosa received the most occurrences $(n=28)$, followed by anorexianervosa $(n=17)$, and eating disorders $(n=15)$. Regarding overall articles $(n=11,322)$, total 16,267 keywords were used in which 2479 keywords met the criteria of minimum five occurrences, the co-occurrence analysis of all keywords indicated that 'anorexia nervosa' received the maximum occurrences $(2,856)$, followed by the keyword, eating disorders (2,738 occurrences), and 'anorexia-nervosa' with 2,478 occurrences (Figure 8). 


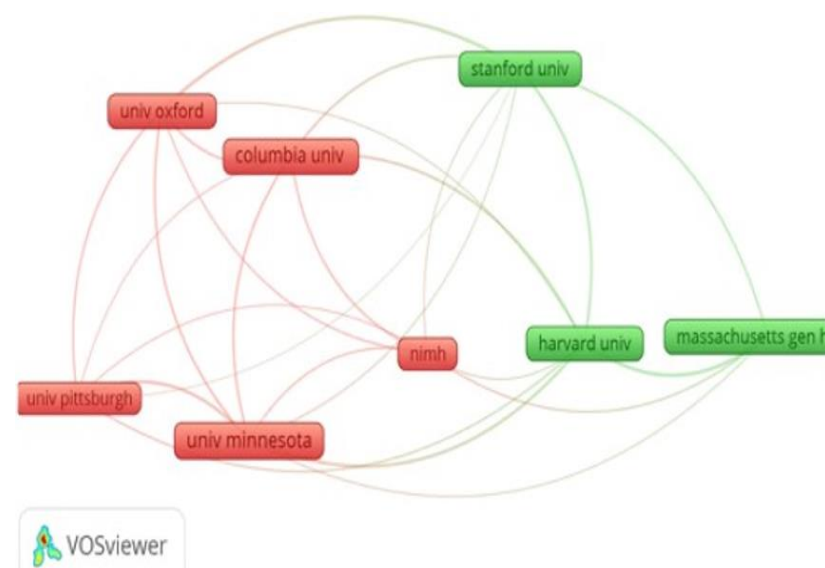

Figure 9. Citation analysis of organizations (top-100 most cited articles)

The citation network analysis of the organizations involved in top-100 most cited articles is shown in (Figure 9). Total 122 organizations were engaged in top-100 most cited articles on eating and feeding disorders, out of which eight met the threshold with minimum five number of documents (Table 5). The University of Minnesota in USA was the leading organization with $(n=12)$ number of documents followed by Columbia University ( $n=9$ articles) and Harvard and Standford university ( $n=8$ articles each). In overall articles, a total of 6,202 organizations contributed to the work related to eating and feeding disorders out of which 889 organizations published atleast five documents. The citation network analysis (Figure 10) showed that Harvard university in USA was the most leading institution with total 405 publications and received 26348 citations followed by King's College London (391 documents, 14,744 citations) and The University of Minnesota (349 documents, 19,528 citations).

\section{DISCUSSION}

Eating disorders (EDs) are not among the lifestyle choices but medical illnesses that influenced biologically. About $80 \%$ of patients with ED suffered from long-lasting effects of reduced mental and physical health comorbidities, it affects up to $3 \%$ of the population however the prevalence varies according to subtypes and populations [37,38]. Anorexia nervosa (AN), bulimia nervosa (BN), and binge eating disorder (BED) are the clinical conditions that appear in adolescence and adult age and are considered disorders with major health consequences, restrictive dieting, depression and even death $[39,40]$. Bibliometric analysis examines the characteristics of published articles based on certain consistent factors and present useful information to authors about the classics of all papers [41]

This is the first comprehensive biblometric analysis summerizing the significant features of most influential studies on eating and feeding disorders. In this study, we systematically analyzed the characteristics of the top-100 most cited articles and the earliest one among these top-100 most cited paper was published in year 1962 [42].

The most important criteria to be considered for evaluating authors contribution is the number of publications. In our analysis Fairburn CG from Oxford University was found to be the most prolific author who significantly contributed to the area of eating and feeding disorders by publishing maximum

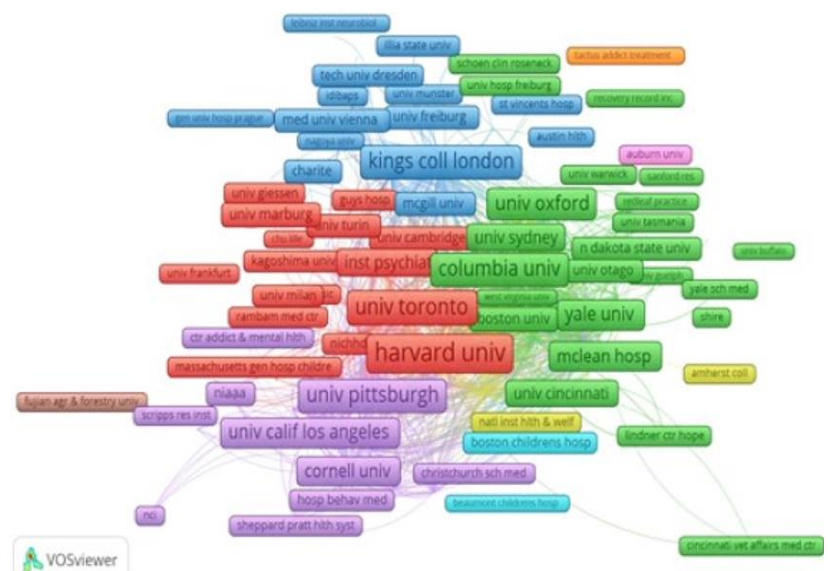

Figure 10. Citation analysis of organizations (overall articles)

articles and received highest citations among top-100 most cited papers. Doll HA from Oxford University and Herzog DB from Harvard Medical School were the second leading authors with same number of publications in research area of EDs and retrieving more information about the research directions of these researchers will grasp more knowledge about the latest trends in this field.

Globally 17 distinct research categories related to Eating and feeding disorders were found among top-100 most cited papers (Figure 3). The research categories, psychiatry (70\%) and psychology (26\%) were found to be more common following nutrition dietetics (14\%) and general internal medicine (12\%). This indicated that the qualities of studies done in the categories of psychiatry and psychology resulted in an interesting and important finding embraced by other researchers.

Being a broad range disorder, the top-100 most cited articles on eating and feeding disorders were published in 32 different journals in which Archives of General Psychiatry was the leading source with maximum publications (20\%) while the analysis of the overall articles showed that International Journal of Eating Disorders was the most productive journal in the area of feeding and eating disorders. Our findings are inline with one of the other studies in the area of psychiatry [43], which showed that authors prefer the relevancy and impact factor more than the citation scores of the journal. However, a few core-journals in specialized field were used for citation analysis and as indicated by Bradford's law, significantly low number of citations were obtained from noncore journals [44]. Which might be explained by the high worth of articles in these journals, or maybe the intrinsic prejudice that investigators picked the high impact factor journals for citation purposes [45]. The three leading sources of publications among top-100 most cited articles belonged to USA which indicated fruitful contribution in the field of eating and feeding disorders as compared with other countries (Table 4). However, it cannot be neglected that the importance of a journal in a specific field is being shown by its impact factor, which represent its quality [46].

A total of 121 institutions took part in publication of top100 most cited articles on eating and feeding disorders. The University of Minnesota was the most prominent institution by publishing larger number of documents and thus received maximum citations. However, it is not important that an institute will depend on the number of publications for citation purposes. Oxford University received more citations with low 
number of publications as compared to Columbia University, Harvard University, and Standford University (Table 5).

Bulimia nervosa was the highly occurred keyword among top-100 most cited articles, indicated that rather than other classes of eating disorders the researchers are much more interested in filling the gaps in knowledge regarding bulimia nervosa (Figure 7). However, the co-occurrence network analysis of all keywords among overall articles ( $n=11,322)$ suggested that 'anorexia nervosa' has been the most common eating disorders for years and has historical importance.

The citation analysis of organizations involved in publishing more documents in eating and feeding disorders among top-100 most cited articles concluded that The University of Minnesota offered more efforts to cover the research trends in eating disorders and received great importance, while the results of that citation analysis of the overall articles indicated that Harvard University has played a key role in documentation of the research gaps regarding eating and feeding disorders.

This study indicated that USA was the publishing leader in writing about eating and feeding disorders and the trend was followed by England, Canada, and the Netherlands. However, more efforts are needed from other developed countries. USA was also found the leading country in countries co-authorship analysis of overall articles retrieved from our search strategy suggesting that authors collaboration in USA is much higher than other countries. These findings are in line with several other studies having diverse fields of research $[47,48]$ suggesting that USA is playing a key role in delivering the latest trends in eating and feeding disorders. However, it cannot be neglected that due to high fundings in research as well as high economic scale and an advanced level of scientific research, USA has always been a global scientific leader in promoting international cooperation with other countries [49-51].

\section{CONCLUSION}

This study is of great value presented a range of analyses on the top-100 most cited studies and overall research output from 1900 to 2020 in eating and feeding disorder. Furthermore, this study might be helpful for the researcher to identify research trends with highly cited articles in our study. The total number of publications in eating and feeding disorders is rapidly increasing over the years. The most studied research area was Psychiatry. In eating and feeding disorders, the contributions of developed countries are far away from that of developing countries. Therefore, strong research collaboration among researchers and institutions from developing countries need to be established with developed countries.

\section{Strength and Limitations}

The current study has few strengths and limitations. In this study, the overall and as well as the top- 100 most cited studies were evaluated to understand the global research trends, most studied research areas, publication frequency and citations count. Some limitations are; firstly, the data used in the current study were retrieved from a single database by using the other databases such as Google Scholar, PubMed, and Scopus may alter the publication frequency and citations count. Secondly, the search was limited to publication published in English language. Further studies are recommended to compare the publication growth and citations frequency among different databases.

Author contributions: All authors have sufficiently contributed to the study, and agreed with the results and conclusions.

Funding: No funding source is reported for this study.

Declaration of interest: No conflict of interest is declared by authors.

\section{REFERENCES}

1. Balasundaram P, Santhanam P. Eating Disorders. 2021 Jun 29. In: StatPearls [Internet]. Treasure Island (FL): StatPearls Publishing; 2021 Jan. PMid:33620794

2. Treasure J, Duarte TA, Schmidt U. Eating disorders. Lancet. 2020;395(10227):899-911. https://doi.org/10.1016/S01406736(20)30059-3

3. Udo T, Grilo CM. Prevalence and correlates of DSM-5 defined eating disorders in a nationally representative sample of U.S. adults. Biol Psychiatry. 2018;84(5):345-54. https://doi.org/10.1016/j.biopsych.2018.03.014 PMid: 29859631

4. Tomoko U, Grilo CM. Psychiatric and medical correlates of DSM-5 eating disorders in a nationally representative sample of adults in the United States. Int J Eat Disord. 2019;52(1):42-50. https://doi.org/10.1002/eat.23004 PMid: 30756422

5. American Psychiatric Association. Diagnostic and Statistical Manual of Mental Disorders, 5th ed. Washington, DC; American Psychiatric Publishing, 2013. https://doi.org/10.1176/appi.books.9780890425596

6. Stembo L. Das Röntgogramm eines metallischen Esslöffels in der Speiseröhre eines erwachsenen Geisteskranken. Dtsch Medizinische Wochenschrift. 1900 Nov 29;26(48):7745. https://doi.org/10.1055/s-0029-1204129

7. Lutter M. Emerging treatments in eating disorders. Neurotherapeutics. 2017 Jul;14(3):614-22. https://doi.org/ 10.1007/s13311-017-0535-x PMid:28547702 PMCid: PMC5509630

8. Lindvall Dahlgren C, Wisting L, Rø $\varnothing$. Feeding and eating disorders in the DSM-5 era: A systematic review of prevalence rates in non-clinical male and female samples. J Eat Disord. 2017;5:56. https://doi.org/10.1186/s40337017-0186-7

9. Walsh BT, Attia E, Glasofer DR. Eating disorders: What everyone needs to Know ${ }^{\circledast}$, Oxford University Press, 2020.

10. Lipson SK, Sonneville KR. Eating disorder symptoms among undergraduate and graduate students at 12 U.S. colleges and universities. Eat Behav. 2017 Jan;24:81-8. https://doi.org/10.1016/j.eatbeh.2016.12.003 PMid: 28040637

11. Thomas J, O'Hara L, Tahboub-Schulte S, Grey I, \& Chowdhury N. Holy anorexia: Eating disorders symptomatology and religiosity among Muslim women in the United Arab Emirates. Psychiatry research. 2018; 260:495-9. https://doi.org/10.1016/j.psychres.2017.11.082

12. Napolitano MA, Himes S. Race, weight, and correlates of binge eating in female college students. Eat Behav. 2011; 12(1):29-36. https://doi.org/10.1016/j.eatbeh.2010.09.003

13. Anna NEV, Anawati ND, Azizi NAN. Analysis of bibliometrics research in library philosophy and practice from 1998-2021. Library Philosophy and Practice (ejournal). 2021:5380. https://digitalcommons.unl.edu/libphilprac/5380 
14. Hulme EW. Statistical bibliography in relation to the growth of modern civilization: Two lectures delivered in the University of Cambridge in May, 1922. London: Printed for the author by Butler \& Tanner. 1923.

15. Gosnell CF. Obsolescence of books in college libraries. Coll. Res. Libs. 1944;5(2):115-25. https://doi.org/10.5860/crl_05_ 02_115

16. Pritchard A. Statistical bibliography or bibliometrics? J Doc. 1969;25(4):348-9.

17. Raisig LM. Statistical bibliography in the health sciences. Bull Med Libr Assoc. 1962;50(3):450-61.

18. Pritchard A. Statistical bibliography; an interim bibliography. North-Western Polytechnic, School of Librarianship. 1969; 60p. (SABS-5; PB 184 244).

19. Sean BE. An Introduction to Bibliometrics and Informetrics. IGI Global, 2009, pp.1-35. http://doi:10.4018/978-1-59904738-6.ch001

20. Luukkonen T. Bibliometrics and evaluation of research performance. Ann Med. 1990;22(3):145-50. https://doi.org/10.3109/07853899009147259

21. Ellegaard O, Wallin JA. The bibliometric analysis of scholarly production: How great is the impact? Scientometrics. 2015;105:1809-31. https://doi.org/10.1007 /s11192-015-1645-z

22. Yu D, He X. A bibliometric study for DEA applied to energy efficiency: Trends and future challenges. Appl Energy. 2020;268:115048. https://doi.org/10.1016/j.apenergy.2020. 115048

23. Leefmann J, Levallois C, Hildt E. Neuroethics 1995 -2012. A bibliometric analysis of the guiding themes of an emerging research field. Front Hum Neurosci. 2016;10:336. https://doi.org/10.3389/fnhum.2016.00336

24. Liu B, Feng R, Liu A, Dong L. Science mapping approach to assisting the review of MineWater disaster prediction and evaluation in China between 2009 and 2019. IOP Conf Ser Earth Environ Sci. 2020;446:052041.

25. Bornmann L, Marx W. Critical rationalism and the search for standard (field-normalized) indicators in bibliometrics. J Informetr. 2018;12(3):598-604.

26. Grover S, Gupta BM. Eating disorders research in India: A bibliometric assessment of publications output during 2000-2019. J Mental Health Hum Behav. 2021;26:74-7.

27. Valderrama-Zurián JC, Aguilar-Moya R, Cepeda-Benito A, Melero-Fuentes D, Navarro-Moreno MÁ, et al. Productivity trends and collaboration patterns: A diachronic study in the eating disorders field. PLoS One 2017;12:e0182760. https://doi.org/10.1371/journal.pone.0182760

28. Soh NL, Walter G. Publications on cross--cultural aspects of eating disorders. J Eat Disord. 2013;1:4. https://doi.org/10.1186/2050-2974-1-4

29. Strand M, Bulik CM. Trends in female authorship in research papers on eating disorders: 20-year bibliometric study. BJPsych Open 2018;4:39-46. https://doi.org/10.1192/bjo. 2017.8

30. Lipsman N, Woodside DB, Lozano AM. Trends in anorexia nervosa research: an analysis of the top 100 most cited works. Eur Eat Disord Rev. 2014;22(1):9-14. https://doi.org/10.1002/erv.2270

31. Aksnes DW, Langfeldt L, Wouters P. Citations, Citation Indicators, and Research Quality: An Overview of Basic Concepts and Theories. SAGE Open. 2019;9(1):1-17. https://doi.org/10.1177/2158244019829575
32. Donthu N, Kumar S, Mukherjee D, Pandey N, Lim WM. How to conduct a bibliometric analysis: An overview and guidelines. J Bus Res. 2021;133:285-96.

33. Ahmad T, Murad MA, Nasir S, Musa TH, Baig M, Hui J. Trends in hepatitis A research indexed in the Web of Science: a bibliometric analysis over the period from 1985 to 2019 . Hum Vaccin Immunother. 2021 Sep 2;17(9):3221-9. https://doi.org/10.1080/21645515.2021.1914804

34. Ahmad T, Hua L, Khan M, Nabi G, Khan S, Çinar IÖ, Haroon, Jalal S, Baig M, Jin H, Wang X. Global Research Trends in Pediatric Trauma From 1968 to 2021: A Bibliometric Analysis. Front. Pediatr. 2021;9:762531. https://doi.org/10.3389/fped.2021.762531

35. Fairburn CG, Beglin SJ. Assessment of eating disorders: interview or self-report questionnaire? Int J Eat Disord. 1994 Dec;16(4):363-70. PMid:7866415

36. Garner DM, Olmstead MP, Polivy J. Development, and validation of a multidimensional eating disorder inventory for anorexia nervosa and bulimia. Int $\mathrm{J}$ Eating Disord. 1983;2(2):15-34. https://doi.org/10.1002/1098-108X(1983 21)2:2<15::AID-EAT2260020203>3.0.CO;2-6

37. Galmiche M, Déchelotte P, Lambert G, Tavolacci MP. Prevalence of eating disorders over the 2000-2018 period: a systematic literature review. Am J Clin Nutr. 2019 May 1;109(5):1402-13. https://doi.org/10.1093/ajcn/nqy342 PMid:31051507

38. O'Brien KM, Whelan DR, Sandler DP, Weinberg CR. Eating disorders and breast cancer. Cancer Epidemiol Biomarkers Prev. 2017 Feb;26(2):206-11. https://doi.org/10.1158/10559965.EPI-16-0587 PMid:27756775 PMCid:PMC5296273

39. Kazim AA, Almarzooqi MS, Karavetian M. The prevalence and determents of eating disorders among emirati female students aged 14-19 years in Ajman, UAE. J Food Nutr Disord. 2017;6:2. https://doi.org/10.4172/23249323.1000222

40. Garrusi B, Baneshi MR. Eating disorders and their associated risk factors among Iranian population - a community based study. Glob J Health Sci. 2012 Dec 10;5(1):193-202. https://doi.org/10.5539/gjhs.v5n1p193 PMid:23283053 PMCid:PMC4776975

41. Kelly JC, Glynn RW, O'Briain DE, Felle P, McCabe JP. The 100 classic papers of orthopaedic surgery: a bibliometric analysis. J Bone Joint Surg Br. 2010 Oct;92(10):1338-43. https://doi.org/10.1302/0301-620X.92B10.24867 PMid: 20884968

42. Bruch H. Perceptual and conceptual disturbances in anorexia nervosa. Psychosomatic Med. 1962;24:187-94. https://doi.org/10.1097/00006842-196203000-00009

43. García-García P, López-Muñoz F, Rubio G, Martín-Agueda B, Alamo C. Phytotherapy and psychiatry: bibliometric study of the scientific literature from the last 20 years. Phytomedicine. 2008 Aug;15(8):566-76. https://doi.org/ 10.1016/j.phymed.2008.04.014 PMid: 18583120

44. Brookes B. Bradford's Law and the Bibliography of Science. Nature. 1969;224:953-6. https://doi.org/10.1038/224953a0

45. Salinas S, Munch SB. Where should I send it? Optimizing the submission decision process. PLoS ONE. 2015;10(1): e0115451. https://doi.org/10.1371/journal.pone.0115451

46. Seglen PO. Citations and journal impact factors: questionable indicators of research quality. Allergy. 1997; 52(11):1050-6. https://doi.org/10.1111/j.1398-9995.1997.tb 00175.x 
47. Yang W, Zhang J, Ma R. The prediction of infectious diseases: A bibliometric analysis. Int J Env Res Public Health. 2020;17(17):6218. https://doi.org/10.3390/ijerph 17176218

48. Wang R, Weng LM, Peng MS, Wang XQ. Exercise for low back pain: A bibliometric analysis of global research from 1980 to 2018. J Rehabil Med. 2020 Apr 24;52(4):jrm00052. https://doi.org/10.2340/16501977-2674 PMid:32296852

49. Zyoud SH, Al-Jabi SW, Sweileh WM. Worldwide research productivity of paracetamol (acetaminophen) poisoning: a bibliometric analysis (2003-2012). Human \& experimental toxicology. 2015;34(1):12-23. https://doi.org/10.1177/ 0960327114531993
50. Patiño-Barbosa AM, Bedoya-Arias JE, Cardona-Ospina JA, Rodriguez-Morales AJ. Bibliometric assessment of the scientific production of literature regarding Mayaro. J Infect Public Health. 2016 Jul-Aug;9(4):532-4. https://doi.org/10.1016/j.jiph.2015.10.001 PMid:26573886

51. Zhang L, Zhao W, Liu J, Sivertsen G, Huang Y. Do national funding organizations properly address the diseases with the highest burden? Observations from China and the UK. Scientometrics. 2020;125(2):1733-61. https://doi.org/ 10.1007/s11192-020-03572-9 